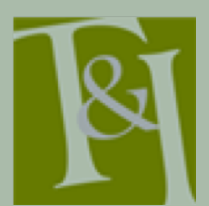

The International Journal for Translation \& Interpreting Research trans-int.org

\title{
Beyond the margins of academic education: identifying translation industry training practices through action research
}

\author{
Begoña Rodríguez de Céspedes \\ University of Portsmouth, UK \\ begona.rodriguez@port.ac.uk
}

DOI : 10.12807/ti.112201.2020.a07

\begin{abstract}
Digital technologies in the translation profession have given rise to the use of automated Computer Assisted Translation (CAT) tools and Machine Translation (MT), and Translation Service Providers are embracing these innovations as part of their workflows. Higher Education Institutions are also transforming their curricula to adapt to the changes brought about by technology (Austermühl, 2006, 2013; Doherty, Kenny, \& Way 2012; Doherty \& Moorkens, 2013; Gaspari, Almaghout, \& Doherty, 2015; Mellinger, 2017; Moorkens, 2017; O’Hagan, 2013; Rothwell \& Svoboda, 2017). This research takes a phenomenological and ethnographical approach using action research as the methodology to see how the new digital skillsets are taught and used in the translation industry. As a trainer -researcher, I stay at translation companies to immerse myself in the training given to new employees. The results of this qualitative-type research derive from observations typically involving the trainer spending a full working week at the employers' premises. The data set is hence collected based on workplace observations within the companies and on semistructured interviews with translation company managers. This approach permits a very full understanding of the skills needed in the translation profession. What has been learned in the workplace can be applied at university in the training of future translators. Preliminary work suggests that MT and Artificial Intelligence (AI), while transforming the profession in many ways, are not yet overriding the need of sophisticated linguistic skills from trainee translators.
\end{abstract}

Keywords: action research; translator training; automation; future proofing.

\section{Introduction and background}

This study analyses the training provided to new translators by Translation Companies (TCs). Translation trainers as researchers can try to elucidate questions that will have an impact on university training programmes of study and the profession. What in-house training is provided by industry? To what extent should industry training practices inform Translation Studies curricula? What balance is there between the need for linguistic and technological skills?

This epistemological approach (how we come to know) is based on action research whose main purpose is to bring innovation from authentic professional contexts into authentic academic training scenarios. By visiting translation companies, university translation trainers become participants to immerse themselves in each TC's training workflow, and can observe patterns by taking field notes and keeping diaries. The main purpose of this type of action research is to future-proof academic translation training practices and to provide an ultimate impact within the profession by facilitating a dialogue between academic and professional trainers. In this article, I illustrate my findings based on visits to translation companies and on in-depth semi-structured interviews with translation company managers in both the United Kingdom and Spain. 
The translation profession has changed because of automation and the rise of new technologies. Translation is not a solely cognitive human act anymore, as there are now tools such as translation memories or machine translation that help optimise translation speed and outputs (Rodríguez de Céspedes, 2018, 2019). As a result, translation companies are increasingly implementing the use of digital tools. According to a survey conducted by the five major European Language Industry Associations and the European Masters' in Translation (2018) less than $1 \%$ of the surveyed companies reported that they are not using Computer Assisted Translation (CAT) tools. This compares with a much higher percentage $(13 \%)$ of individual language professionals who report that they do not employ new technologies. This means that if there is widespread use of CAT tools in the profession, university trainers cannot ignore these developments if the goal is to prepare future professionals for the labour market. Indeed, there has been an increase in the provision of translation technologies teaching across universities in Europe. Rothwell and Svoboda (2017) report, on their survey on translation tools and technologies, that out of the 55 responses they received from universities, 45 of those belonging to the European Masters in Translation confirmed that technologies and tools are being taught in their programmes. The integration of CAT tools has been described, analysed and advocated by translation scholars in the translation studies literature (e.g. see Austermühl, 2006, 2013; Doherty, Kenny, \& Way, 2012; Doherty \& Moorkens, 2013; Gaspari, Almaghout, \& Doherty, 2015; O'Hagan, 2013; Mellinger, 2017; Moorkens, 2017). Hence the question needs to be answered: is technology taking over the traditional language and intercultural skills needed to master the art of translation? And, if so, how far has this process progressed?

This piece of research aims to identify the training provided within the translation industry to new employees, to disseminate findings and to provide translation training in Higher Education that responds to the evolution of the industry in the $21^{\text {st }}$ century. In turn, Language Service Providers will benefit from the line of communication offered by academia to also inform their own training practices.

The general scope of my research considers the current use of translation technologies by TCs in the United Kingdom and Spain, and focuses on the balance given to linguistic and technological competence in the training provided by industry. This study builds on and derives from the first phase of the University of Portsmouth research project (2016-2017): When Translation meets Technologies: Language Service Providers in the Digital Age, where project managers and translation business owners from different UK companies accepted our invitation to take part in focus groups. We sought information on the current use of digital tools by Language Service Providers in the UK ${ }^{1}$, and learned who provides the training in digital tools. Using the qualitative analysis software package N-Vivo to examine our data, we were able to reach a set of conclusions in terms of the type of training provided in digital tools. The general expectations were that new trainee translators have a minimum knowledge of CAT tools and translation memories (mainly learnt at university level) before they join the company, although some TCs provide training via in-house induction packages or internships, and others facilitate their employees' attendance at CAT tools seminars outside the company.

In this second phase of the project, my research takes a different tack. Whilst in the first phase I identified who was training translators in new technologies, in the second phase I analyse what exactly is taught by TCs and what skills are sought after.

I have therefore visited translation companies to explore what it means to translate today, and what the implications for training are. What is the future of

\footnotetext{
${ }^{1}$ For a full report of all the focus groups' thematic areas, see Sakamoto, Rodríguez de Céspedes, Berthaud, and Evans (2017).
} 
translation with automation? Where does university training fit in? What expertise is needed in the short to medium term for translators to work with machines?

Thanks to observational and qualitative methods in translator training, trainers can research these questions in situ to help them go beyond the traditional lines of enquiry in Translation Studies, so that established teaching practices can be challenged and analysed critically, and insights and reflection can be the basis of innovation. This study hence addresses a series of questions with the aim of future-proofing university translation training.

\section{Methodology}

\subsection{Action research}

If one is to question the possibility of finding an interest in using action research in Translation Studies, one inevitably needs to start by questioning what is to be researched in the area and what is calling for action. (Cravo \& Neves, 2007, par. 1)

Translation trainers need to keep up with advances in the translation profession in order to provide curricula that align formal teaching with industry practice and demands, and with the realities of the professional world. Furthermore, a responsible trainer takes innovative steps to regularly update content to reflect the evolution of the discipline. Action researchers start a project with a curiosity to learn something new and to act upon it. For this study, my aim was to find out what training is provided by TCs to better understand the needs of future translators and what academia can do for them. Carr and Kemmins (1986, p. 162) define action research as "a form of self-reflective enquiry undertaken by participants in order to improve the rationality and justice of their own practices, their understanding of these practices and the situations in which the practices are carried out".

Action research follows a cycle described by $\operatorname{McNiff}(2013$, p. 90) whereby researchers as participants review their practices to identify an aspect or aspects that need investigating. Research questions are formed followed by a systematic collection of data. The next step involves the analysis of data, and finally trainers reflect and act upon the data to reconsider practices in light of the evaluation. As it is commonplace in ethnographic studies, the narrative for this study will be primarily descriptive as it is based on the researcher's collected data and its interpretation. However, unlike recent translation studies focussing on the "who" (see for example Abdallah, 2012; Koskinen, 2008; Risku et al., 2013) and which draw from the actor-network theory of Latour, here the focus is on the "what". As McNiff (2013, p. 25) puts it: "The 'action' of action research refers to what you do, and the 'research' of action research refers to how you find out about what you do." (my emphasis).

\subsection{Observations and interviews: why are they useful in translation studies research?}

In my study, I conducted in-house observations and follow-up interviews, which are two types of qualitative methods used in action research. Observations allow for an in-depth understanding of the object under research. There are a number of reasons why a translator trainer can benefit from carrying out and participating in observations at translation companies: to reflect upon their own teaching; refresh their understanding of professional trends; engage in critical thinking; advance their professional development and expertise; provide a channel of communication with industry stakeholders; update the 
curriculum (research-informed teaching); share findings with students and peers; and to witness first-hand the evolution of the profession.

Interviews often complement observations, as they provide in-depth insights into people's perceptions and experiences - something that questionnaires, for example, cannot provide. Furthermore, observations allow for witnessing behaviours, whereas interviews yield information on individuals' thinking (Heigham \& Crocker, 2009).

\section{Observations and interviews at translation companies}

\subsection{Settings}

After receiving a favourable ethics review from the university's Faculty Ethics Committee, I visited two translation companies, one each in the UK and Spain, as a pilot study to conduct observations. The aim was to shadow a new trainee translator during their induction week in the company. There are several factors to consider when planning to approach TCs to conduct research on their premises. Apart from the preparation and submission of documents needed beforehand to clear any ethical issues such as confidentiality (a process that may take several weeks), there are also logistical steps to consider. First, it is not always straightforward to fit into the company's training cycle, since one needs to follow the induction of a new employee for a few days at a time (it could happen anytime in the year). For this study the timeframe set aside for observations was a week at each company. Second, not all companies will be willing to open their doors to academics (unless the academic establishes a good working relationship first). Hence, depending on the context, it may not always be possible for trainers to observe real-life practices outside the classroom, unless the trainer works in industry and academia at the same time, or if there is a strong emphasis on the part of the company to collaborate with universities. The latter case applied with the companies observed for this study, as they collaborate with universities at national and international level, and invest in their employees by providing in-house training. The companies have more than 300 customers worldwide and have main offices in the UK and Spain but branches in other countries. They are both leaders in the Language Service Provider (LSP) sector in northern and southern Europe respectively as Regional Language Vendors (RLVs). They work with direct clients and for Multilingual Language Vendors (MLVs) - big, well-known multinationals who need to localise their texts into various languages. Both companies have a respective team of in-house and freelance translators, and implement consolidated working digital environments and workflows.

\subsection{Observations}

I was invited to take part in the trainees' induction by sitting in the same rooms, attending the same presentations, going through their induction materials (and learning objectives), and observing whilst they carried out their first translations at the company. I used my laptop computer to take field notes where I diarised not only what I saw (descriptive account of induction learning content and objectives) but also what I experienced by adding my own impressions as I went along. This approach draws from Phenomenology (Finlay, 2008, 2009) where the observer sees things with fresh eyes to imbue herself with the novelty of the new training surroundings. This facilitates an open mind to engage and go beyond the trainer's already established knowledge. To that effect, some of my 'on the spot' spontaneous musings and reflections appear on the screen in different colours to separate them from factual information. This is so that both sets of data (factual and reflective) can be analysed and contrasted later in the process. 
3.2.1 Findings: The enriching experience of observing real-life authentic training practices in the workplace allows for an insight into processes, procedures and behaviours. In this section, I would like to highlight what the observational data revealed in terms of two areas: the use of technologies, and quality assurance. These areas will help elucidate answers to my research questions.

3.2.1.1 Technologies: In terms of technologies, both companies make effective use of CAT tools and translation memories in their workflows, and have their own in-house project management software system. I will call them company $\mathrm{A}$ and company B for ease of reference from now on. Company A alone uses more than twenty different CAT tools, but the CAT tools used most commonly by both companies (A and B) are: Memo Q, SDL Trados Studio 2017, Across, Passolo 2011, MemSource and Google GTT. Some tools are installed on the desktop (old style) needing local installation and files (for example SDL Trados Studio, Idiom); others have online connection and logins, for example Google; but there is also a hybrid needing both online and local installation. Company A uses MT and offers services in MT post-editing.

The first day of induction was similar for both trainees as they covered the main company policies, and an introduction to the tools and in-house processes. Induction takes place with a combination of face-to-face tutorials, live or recorded webinars, and self-studies. Company A uses more than one trainer led by a learning and development manager dealing with different training aspects; company B has its own learning officer who oversees all aspects of induction of the new trainees. Progress in relation to familiarisation with CAT tools is closely monitored daily, and trainees start with translation tasks from day 1. One notable difference was that the trainee in company A started completing translation exercises where CAT tools had already populated some previous segments; whereas the trainee in company B was asked to translate content from scratch by using a CAT tool and sending queries to the trainer whilst in the process of simulating a real-case scenario. The trainee in company B had previous knowledge of CAT tools (learnt at university) but the trainee in company A did not.

Trainees in both companies work with authentic (already translated texts) for which they receive feedback from day one of their training. They are subsequently progressed onto the translation of real commissions after a series of training stages. Company B differentiates these stages into:

- practice tasks: to familiarise trainees with the company workflow systems: uploading commissions including files, installing CAT tools including translation memories, and translating from scratch.

- cloned tasks: these are real commissions, as received by the customer, which the trainee translates under the close supervision of the training team.

- real tasks: the trainee takes on real commissions, but translations are still supervised by a senior translator.

The main aims of the training processes are the enhancement of the trainee's technical expertise (CAT tools and company's working environment), on a par with the practice of (leading to mastery of) translation techniques as we will see in the next section. Depending on language combination, language direction and specialisations, trainees are expected to be proficient without direct supervision within 1-2 years of initial company training, although all their work continues to be revised and graded as we will see below.

3.2.1.2 Quality assurance: Quality Assurance (QA) is generally complex as it involves a series of quality controls to make professional translation services fit for purpose. Accuracy and sticking to customer's briefs and deadlines are only one part of this vital industry requirement. How accuracy and quality are 
measured varies from one TC to another. For an overview of the evolution of Translation Quality Assessment (TQA) in the profession and the current state of play, including details of the Multidimensional Quality Metrics (MQM), see Lommel (2018).

In fact, both companies have consolidated quality management systems in place to address error analysis, including scores for each type of error. Company A uses the TAUS Dynamic Quality Framework, the EU-funded QT Launchpad and Multidimensional Quality Metrics which classifies errors according to their typology. Both companies have been certified with ISO (International Organization for Standardization) 17100 proving that they have effective, stringent and established quality assurance and management systems in place. It stands to reason then that accuracy and usability of translated texts are vital for the business success of the companies. Trainees are expected to receive feedback on work which is graded in the same way that established translators have their translations scored (to the extent that they can even 'fail' an assignment).

Company B gave a detailed description of both internal and external QAs following LISA (Localization Industry Standards Association). Errors are divided into critical ( 1 critical point is enough for the translation to fail), major (scoring up to 5 points) and minor (1 point). Internal feedback is sent back to the translator in a series of scenarios based on the reviewer's score: major (failed assignment); five points or over with considerable errors; and if the reviewer feels that it needs to be revised by the translator. A QA form has a similar format to the grid below (Table 1):

Table 1. Error analysis typology (linguistic) Company B

\begin{tabular}{|l|l|l|l|l|l|}
\hline $\begin{array}{c}\text { Error } \\
\text { category }\end{array}$ & Minor & Major & Critical & Total & $\begin{array}{c}\text { Max. } \\
\text { allowed }\end{array}$ \\
\hline Mistranslation & & & & & \\
\hline Accuracy & & & & & \\
\hline Terminology & & & & & \\
\hline Language* & & & & & \\
\hline Style & & & & & \\
\hline Country* & & & & & \\
\hline Consistency & & & & & \\
\hline
\end{tabular}

${ }^{*}$ Grammar, semantics, spelling, punctuation ${ }^{* *}$ Dialect or regional varieties (extremely important when texts are localised)

The external QA is carried out by the client, who makes recommendations and feedback that needs to be taken on board by the translator before re-sending. The client has the last say on what the target text content will be like. There have been cases where translators or the TC reviewers may disagree on the translation of certain terms that are unidiomatic for example. Translated texts will go back and forth until a compromise has been reached on the last version.

\subsection{Interviews}

Interviews complement the observational pilot studies by offering a holistic overview of the state of play of in-house training in translation companies, including the two that I observed. Eight translation managers from the UK and Spain (including those from the observed TCs) agreed to be interviewed. One of the interviews was much briefer than the rest but produced some valid comments that I will reproduce later in the findings. To anonymise responses, 
each participant will appear as P1 (participant 1) to P8 (participant 8) when they are quoted. These were the semi-structured interview questions:

$>$ What are you looking for in a translator? What qualities? Any different qualities between in-house/freelance translators?

$>$ What competences are demanded today by industry? And in the next 5-10 years?

$>$ How important is linguistic performance/competence when recruiting a new member of staff?

$>$ How do you test technological skills in new/prospective employees?

$>$ How do you test linguistic skills in new/prospective employees?

$>$ How long is the in-house training period?

$>$ What will be, in your opinion, the impact of artificial intelligence and automation in the translation profession?

$>$ Will linguists still be needed? What for?

$>$ What can universities still do in terms of training?

\subsubsection{Findings from interviews}

3.3.1.1 Profile of the trainee: Apart from excellent language skills working into the mother tongue, (requisite number one) and technical ability (secondary), companies look for certain soft skills in their employees such as aptitude, positive attitude, common sense, proactivity, reactivity, flexibility, adaptability, teamwork, decision making and ability to accept criticism in a positive fashion.

Although the same qualities are expected from freelance translators, three participants (P1, P3 and P5) commented on the good reputation that the company gains when having a robust in-house training programme in place. Three participants (P1, P3 and P5) said that the only difference between having new in-house translators and freelancers is that we can "mould an in-house translator to meet our requirements" and "we can support them to becoming full-fledged professional translators". P3 mentioned that when some fields are highly specialised (i.e. patents) they have recruited a highly trained engineer without previous translation practice as "we were able to teach him the "rules' and terminology of patent language and he has become an excellent resource". Generally, however, linguistic performance is far more important in most other subject fields.

Concerning technological competence (CAT tools), there is a divide between those companies who include in-house training of this competence and those who expect previous knowledge and recruit new translators who have covered tools in their postgraduate courses (P2, P4). P7 and P8 are the only translation managers from companies that do not provide in-house training, and rely on their freelancers to use CAT tools when necessary. The case of P7 is interesting as s/he admitted that: "At the moment, the use of CAT tools is not required, although I know that many of our competitors insist upon it".

3.3.1.2 Testing competences: The interviewed managers reported that their companies use a variety of activities to test linguistic and technological competences before recruiting new translators, as can be seen in Table 2. Basic technological aptitude is expected from trainees if there is no specific company test to check for familiarisation with technological tools. In some cases, CATtool training is provided in-house or via external accreditation from outside providers. UK TCs assess candidates on their aptitude and potential, not perfection in their translation skills and abilities, and the same applies to technological aptitude. By contrast, Spanish companies have very high expectations of their new trainees (both linguistically and technologically). The reason may be that translation is a popular field taught at universities. The twenty-six Spanish universities where translation is taught at undergraduate level offer translation skills with a prominent load in the curriculum. In their 
study, Álvarez-Álvarez and Arnáiz-Uzquiza (2017) confirm that “together with languages, Translation is the most important category in terms of compulsory credit load, covered by up to 70 ECTS on average". Translation Technologies is normally embedded in other subjects at undergraduate level but there are several post-graduate courses specialising in localisation and technologies, so there is a big pool of talent from which Spanish TCs can draw. Conversely, the picture is different in the UK where there is concern about the state of foreign language learning and provision, as there has been a decline in the take up by secondary school students who follow on to study languages and translation at university. This trend will have a direct impact on the availability of future English native-speaker translation professionals in the UK if there is no plan of action to remedy it (European Association of Translation Companies, 2018).

Table 2. Linguistic and technological testing

\begin{tabular}{|c|l|l|}
\hline Participant & \multicolumn{1}{|c|}{ Linguistic competence test } & Technological competence test \\
\hline P1 & $\begin{array}{l}800 \quad \text { word-test (IT, technical, } \\
\text { commercial) }\end{array}$ & None \\
\hline P2 & $\begin{array}{l}\text { Translation of glossary terms, } \\
\text { translation of instructions, translation } \\
\text { of tags, revision of a translated text, } \\
\text { specialised translation test (to choose } \\
\text { from: legal, marketing, automotive, IT, } \\
\text { biomedical) }\end{array}$ & None (expected) \\
\hline P3 & Test in a specialised area & None \\
\hline P4 & $\begin{array}{l}\text { Test that is revised, reviewed and } \\
\text { scored (simulating real practices) }\end{array}$ & $\begin{array}{l}\text { Tests reproducing real-world } \\
\text { working environments (CAT tool } \\
\text { and different formats) }\end{array}$ \\
\hline P5 & $\begin{array}{l}\text { Timed test translation as part of the } \\
\text { interview (genres they cover) }\end{array}$ & None \\
\hline P6 & Translation test with deadline & Basic check of use of tools \\
\hline P7 & Test translation to freelancers & None (expected) \\
\hline P8 & Short translation test & None \\
\hline
\end{tabular}

3.3.1.3 What does the future hold? All but two of the companies which provided interviews are certified by ISO 17100, the International Organization for Standardization that "provides requirements for the core processes, resources, and other aspects necessary for the delivery of a quality translation service that meets applicable specifications". These standards provide a guarantee that a company meets certain criteria that are applicable to current professional practices. Automation has already heavily influenced the profession (translation memories, client portals, project management systems, etc.) and artificial intelligence will influence what type of work can be left to human translators; accordingly, standards will also be updated as the profession evolves.

At present, the companies surveyed in this study still put linguistic competence in L1 and L2 before technical and technological skills, and there is a consensus that in the very near future more diverse linguistic qualities will be needed especially around the areas of post-editing, highly specialised subject area knowledge, and transcreation skills. This means that highly trained language professionals will be needed for various roles: to review the output produced by MT, to make creative marketing communications or brochures, and to produce translated texts in very regulated domains such as the pharmaceutical or legal fields. There will be also a place for premium translation and also content creation, whereby the professional linguist takes a client's brief and produces a localised product from scratch. 
The analogy that participant P5 makes between high-end or premium translation and bulk translation serves as an illustration of the general feeling shared by all participants and by many industry stakeholders in terms of where the industry is heading:

[P5] If you compare human translation to a finely crafted Chippendale chair - you use the best wood, the best craftsman, and pay appropriately for the excellent product you receive. It is perfectly fit for purpose and is long-lasting and attractive to the eye. But such high-quality furniture will not remove IKEA from the market. Similarly, flat-pack translations have their place in the industry but won't remove the need for hand-crafted Chippendale translations.

There were also comments from interviewees below that resonate with Pym's claim (2013) that technology has challenged the nomenclature that defines the role of a translator:

$[\mathrm{P} 4][\ldots]$ the profile is evolving towards a more technological profile due to MT and AI requirements.

[P5] As for the coming years, time will tell whether the industry will make a move to the general downgrading of translation from "skilled profession" to "fixing Google's efforts."

3.3.1.4 Matching academic and industry expectations- where do we go from here? Is there a space in the translation curriculum to fit all the competences required by industry? This question builds on from the work conducted by the PACTE group and the European Master's in Translation spin-off projects such as OPTIMALE. Is academia ready to embrace the challenges posed by automation and AI? How about preparing students for new translation-related professions? Certainly, translation students need to be aware of the technologies currently used by translation companies. Therefore, they need to know what is expected of them if they decide to become freelance or in-house translators, and also possess a basic knowledge of the nature of the work. Meeting tight deadlines, learning about the fast-paced nature of the job and developing soft skills (Rodríguez de Céspedes, 2017) will give them a head start upon graduation.

The observations in this study have confirmed the extreme importance that translation companies give to QA. It is an area that needs further exploration in the translation training curriculum (Doherty et al., 2018). Indeed, I did not get the chance to explore the QA system used for analysis of feedback from the client's perspective (only the internal, company one), and this could well be the subject of further research. However, I contrasted the error typology assessment categories against the scores used for internal and feedback in translation companies, and these can be simulated in the classroom (see table 1 above). Furthermore, academics can collaborate with industry to create translation company simulations and embed them in the curriculum where students take on different roles (translator, project manager and reviewer). Indeed, academic assessment criteria can be adapted to replicate a typical TC error analysis system to prepare students for their future careers.

Another area that can be exploited in the classroom involves students' performing self-assessment practices in their translation learning process. Thanks to the observations, I witnessed how trainee translators received and benefitted from feedback, and how they had to respond to the feedback to learn from their mistakes and hone their translation skills. The trainee is presented with two tables in parallel - one with their final version, and one with the published translation after it has gone through the internal QA system - and must then comment on their errors and give a rationale for their choices. Empirical studies on self-assessment are underrepresented in the translation training literature according to Xiangdong (2018), and its exploration in the 
classroom can prove a powerful learning tool for the development of top translation and linguistic skills.

What about technology? Technologies and CAT tools can also be assessed at university following TC criteria, but the key is to integrate tools where possible in practical translation classes so that, again, real-life scenarios can be simulated (Mellinger, 2017). Huertas Barros and Vine (2018) report that postgraduate courses in the UK are increasingly aligning assessment contents to match industry practices - including use of tools - because of a closer collaboration between academia and industry, general reading of translation academic papers on translator training, and matching of competences based on frameworks such as that of the EMT.

Finally, in order to future-proof translation training and tentatively prepare students for new careers in translation-related jobs, we still need to focus on honing soft skills and foreign-language and mother-tongue expertise (Rodríguez de Céspedes, 2019) by developing writing skills in different genres and for different purposes, as this is something that companies still expect from universities and will conceivably help future-proof the role of the translator.

\section{Conclusions}

This study gives a picture of current training practices, obtained by visiting two translation companies in the UK and Spain. The observed practices may vary depending on geographical context but, for me as a trainer, taking part in action research has proved beneficial as "academics in question regard their practice not as simply communicating subject matters, but also as accepting pedagogical and epistemic responsibility for their work" $\operatorname{McNiff}(2013$, p.5).

The in-company observations were complemented by interviews with eight translation managers from various companies to offer an insight into their thoughts and open a line of communication for future collaboration. Academia cannot keep up with advances in technology in the same way that companies do, due to financial and expertise constraints. However, graduates can have a head-start into their careers if during their academic studies they learn about the tools used in industry, general workflows, and industry expectations. Furthermore, this study confirms that TCs are happy to train their new employees with technological aspects to suit company demands. Academic and industry trainers can exchange best practices for the benefit of future-proofing the profession as this study has illustrated. Firstly, despite all the recent gloom and doom brought about by the impact of automation and AI in our field, academic education can still safely focus on developing language and linguistic skills. Secondly, technology is not taking over the traditional language and intercultural skills needed to master the art of translation. Finally, although a lot of work is being automated, there is a place for linguistic skills in the so-called premium translation, post-editing or creation of localised materials, and consequently academic curricula can also reflect that. In summary, Translation Studies curricula can be informed by industry practices, and all that is needed for this to happen is a dialogue between trainers in academia and industry as evidenced in this paper.

\section{References}

Abdallah, K. (2012). Translators in production networks: Reflections on agency, quality and ethics. Dissertations in Education, Humanities and Theology. 21. Finland: University of Eastern Finland.

Álvarez-Álvarez, S., \& Arnáiz-Uzquiza, V. (2017). Translation graduates under construction: do Spanish translation and interpreting studies curricula answer the 
challenges of employability? In The Interpreter and Translator Trainer. Special Issue: Employability and the Translation Curriculum, 11(2-3), 139-159

Austermühl, F. (2006). Training translators to localize. In A. Pym, A. Perekrestenko, \& B. Starink (Eds.). Translation technology and its teaching (with much mention of localization) (pp. 69-81). Tarragona: Intercultural Studies Group.

Austermühl, F. (2013) Future (and not-so-future) trends in the teaching of Translation Technology. Tradumatica, 11, 326-337.

Carr, W., \& Kemmins, S. (1986) Becoming critical: knowing through action research. London: Falmer Press.

Cravo, A. \& Neves, J. (2007) Action research in Translation Studies. The Journal of Specialised Translation, 7, 92-107. Retrieved from http://jostrans.org/issue07/ art_cravo.pdf

Doherty, S., \& Moorkens, J. (2013). Investigating the experience of translation technology labs: pedagogical implications. Journal of Specialised Translation 19, 122-136. Retrieved from http://www.jostrans. org/issue19/art_doherty.php

Doherty, S., Kenny, D., \& Way, A. (2012) Taking statistical machine translation to the student translator. Proceedings of the 10th Biennial Conference of the Association for Machine Translation in the Americas (AMTA), San Diego, CA, 28 October 1 November 2012). Retrieved from http://www.mt-archive. info/AMTA-2012Doherty-1.pdf

Doherty, S. \& Kenny, D. (2014). The design and evaluation of a Statistical Machine Translation syllabus for translation students. The Interpreter and Translator Trainer, 8 (2), 295-315. Retrieved from https://doi.org/10.1080/ 1750399X.2014. 937571

European Association of Translation Companies (EUATC). (2018, July 5). ATC calls for action to boost UK language learning [Blog post]. Retrieved from https://atc. org.uk/atc-calls-for-action-to-boost-uk-language-learning/

EMT, ELIA, EUATC, FIT, GALA, \& LIND. (2018). Expectations and concerns of the European language industry 2018. Retrieved from https://ec.europa.eu/info/ sites/info/files/2017_language_industry_survey_report_en.pdf

Finlay, L. (2008). Unfolding the phenomenological research process: iterative stages of "seeing afresh". Journal of Humanistic Psychology, 53(2), 172-201.

Finlay, L. (2009). Debating phenomenological research methods. Phenomenology \& Practice, 3(1), 6-25.

Gaspari, F., Almaghout, H., \& Doherty, S. (2015) A survey of machine translation competences: Insights for translation technology educators and practitioners. Perspectives, 23(3), 333-358.

Heigham, J. \& Crocker, R.A. (2009). Qualitative research in applied linguistics. London: Palgrave MacMillan.

International Organisation for Standardization. (2015). ISO 17100:2015 Standards. retrieved from https://www.iso.org/standard/59149.html

Huertas Barros, E., \& Vine, J. (2018) Current trends on MA translation courses in the UK: changing assessment practices on core translation modules, The Interpreter and Translator Trainer, 12(1), 5-24. DOI: 10.1080/1750399X.2017.1400365

Koskinen, K. (2008). Translating institutions. An ethnographic study of EU translation. Manchester: St Jerome.

Lommel, A. (2018). Metrics for translation quality assessment: a case for standardising error typologies. In J. Moorkens, S. Castilho, F. Gaspari, \& S. Doherty (Eds.), Translation quality assessment. From principles to practice (109-127). Switzerland: Springer.

Mellinger, C. D. (2017.) Translators and machine translation: Knowledge and skills gaps in translator pedagogy. The Interpreter and Translator Trainer, 11(4), 280293. DOI: $10.1080 / 1750399 X .2017 .1359760$

Moorkens, J. (2017) Learning about Neural Machine Translation via a comparative evaluation task. Paper presented at the 17th Annual Translation Conference. Translation and Disruption: Global and Local Perspectives. 4 November 2017. University of Portsmouth: Portsmouth.

O'Hagan, M. (2013). The impact of new technologies on Translation Studies: a technological turn? In C. Millán-Varela \& F. Bartrina (Eds.), The Routledge handbook of Translation Studies (pp. 503-518). London: Routledge.

OPTIMALE. (2012). Employer survey. Retrieved from http://www.ressources.univrennes2.fr/service-relations-internationales/optimale/competences-requirements/ employer-survey 
PACTE. (2005). Investigating translation competence: conceptual and methodological issues. Meta, 50(2), 609-619.

Pym, A. (2013). Translation skills-sets in a Machine-Translation age. Meta, 58(3), 487503. http://dx.doi.org/10.7202/1025047ar

Risku, H., Rossmanith, N., Reichelt, A., \& Zenk, L. (2013). Translation in the network economy. In C. Way (Ed.), Tracks and treks in translation studies: Selected papers from the EST Congress, Leuven 2010 (pp. 29-48). Amsterdam: John Benjamins. http://doi.org/10.1017/CBO9781107415324.004

Rothwell, A., \& Svoboda, T. (2017). Results of tools and technologies teaching survey of working group 2. Paper presented at the European Master's in Translation meeting, Dublin City University. Dublin, 21 November 2017.

Rodríguez de Céspedes, B. (2017) Addressing employability and enterprise responsibilities in the translation curriculum. Special issue of the Translator and Interpreter Trainer. Employability in the Translation and Interpreting Curriculum, 11(2-3), 107-122.

Rodríguez de Céspedes, B. (2018). Mind the gap: Language Service Providers' perceptions of the technological training of professional translators. In E. Postigo (Ed). Nuevas tecnologías, procesos cognitivos y estrategias para la optimización de las competencias del traductor e intérprete (pp. 143-161) [New technologies, cognitive processes and strategies to optimize translator and interpreter competences]. Berlin: Frank and Timme.

Rodríguez de Céspedes, B. (2019). Translator education at a crossroads: the impact of automation. Lebende Sprachen, 64(1), 104-122.

Sakamoto, A, B., Rodríguez de Céspedes, S., Berthaud, B., \& Evans, J. (2017). When translation meets technologies: Language service providers in the digital age. [Report]. University of Portsmouth and Institute of Translation and Interpreting. Retrieved from https://www.iti.org.uk/professionaldevelopment/research/ university-of-portsmouth

Xiangdong, L. (2018) Self-assessment as 'assessment as learning' in translator and interpreter education: validity and washback. The Interpreter and Translator Trainer, 12(1), 48-67. DOI: 10.1080/1750399X.2017.1418581 